Aims To collate and assess the existing literature on the role of and barriers to the GP providing shared care for PLWHIV.

Methods MEDLINE, PsycINFO and EMBASE were searched using MESH terms "HIV" or "AIDS" combined with "general practice" or "primary health care". Empirical studies from developed countries relating to the role, involvement or barriers of GP utilisation in shared care were used. Eleven research articles were eligible for this review.

Results Most GPs and patients want to engage in shared care. 81-89\% PLWHIV were registered with a GP and 78\% had disclosed their status. Potential barriers included lack of specialist knowledge, accessibility, issues of confidentiality and stigmatisation, and poor communication between services. GP engagement was dependent on their experience with HIV, local prevalence of HIV and patient level of morbidity.

Conclusions This review demonstrated large variations between UK health service provisions for PLWHIV. Disclosure to GPs has improved in the post-HAART (highly active antiretrovirals) era; however remaining barriers to shared care, primarily communication between services, needs to be addressed. Further research to develop models of shared care for PLWHIV is necessary to provide comprehensive safe, good quality care.

\section{P125 IMPROVING CLINICAL STANDARDS IN GU MEDICINE: A RETROSPECTIVE AUDIT OF NEISSERIA GONORRHOEAE}

Jessica Jefferson*, Sris Allan. Coventry and Warwickshire Partnership Trust, Coventry, UK

\subsection{6/sextrans-2015-052126.168}

Background This was a retrospective analysis of clinic performance in the management and treatment of Neisseria gonorrhoeae (GC) according to current British Association of Sexual Health and HIV (BASHH) guidelines.

Methods All cases of GC diagnosed at our clinic between $1^{\text {st }}$ January and $30^{\text {th }}$ June 2014 were identified. The case notes were reviewed and assessed against current BASHH criteria. This was compared to data collected at the same clinic for the same six months in 2007 to 2014 . The total number of cases identified in 2014 was 126.

Results

Conclusions Current BASHH targets have been achieved in only 1 out of 5 criteria, there was a drop from 100\% (2013) to 97\% (2014) in patients not receiving $1^{\text {st }}$ line treatment. Targets for chlamydia screening/treatment were met. There was very poor performance in offering written advice in 2014 - this is likely due to poor documentation rather than clinical practice. A new facility, implemented during the audit period, on our computer system now gives a visual prompt for recording the provision of written information. This will need to be re-audited in 2015 to look for improvement. We recommend making the input of information to be a compulsory entry before allowing the entry to be saved. Further staff training and awareness of arranging TOC needs to be addressed, and we recommend a re-audit of this next year. We suggest that we should implement a TOC entry facility on our patient record to prompt users to arrange this for the patient.

\section{P126 THE 2014/15 EUROPEAN COLLABORATIVE CLINICAL GROUP (ECCG) SERVICE EVALUATION ON THE MANAGEMENT OF PELVIC INFLAMMATORY DISEASE}

${ }^{1}$ Omome Etomi*, ${ }^{1}$ Sabah Ahmed, ${ }^{1}$ Ben Brooks, ${ }^{2}$ Gilbert Donders, ${ }^{3}$ Mikhail Gomberg, ${ }^{4}$ Peter Greenhouse, ${ }^{5}$ Jorgen Jensen, ${ }^{6}$ Phillipe Judlin, ${ }^{7}$ Jonathan Ross, ${ }^{8}$ Emily Clarke, ${ }^{8}$ Raj Patel. ${ }^{1}$ Southampton Medical School, Southampton, UK; ${ }^{2}$ Antwerp University Hospital, Edegem, Belgium; ${ }^{3}$ Moscow Scientific and Practical Centre of Dermatovenereology and Cosmetology, Moscow, Russia; ${ }^{4}$ Weston Integrated Sexual Health Centre, Bristol, UK; ${ }^{5}$ State Serum Institute, Copenhagen, Denmark; ${ }^{6}$ University Hospital Nancy, Nancy, France; ${ }^{7}$ University Hospitals Birmingham, Birmingham, UK; ${ }^{8}$ Royal South Hants Hospital, Southampton, UK

\subsection{6/sextrans-2015-052126.169}

Background Pelvic Inflammatory Disease (PID) describes a broad spectrum of disease primarily diagnosed clinically, with signs and symptoms lacking both specificity and sensitivity. Mycoplasma genitalium (MG) is being increasingly implicated in cases of non-chlamydial non-gonococcal PID. The core principle of the management of PID remains to maintain a low threshold for diagnosis and treatment to prevent long-term sequelae.

Aim To evaluate the current management of PID amongst sexual health physicians across Europe against the current European guidelines.

Methods A clinical scenario based questionnaire was developed by a panel of European experts on PID, and this was disseminated to a group of 120 sexual health physicians across 38 countries who are members of the European Collaborative Clinical Group (ECCG) - a network of sexual health specialists who conduct questionnaire based research across the European region.

Results Provisional results demonstrate variation in practice across Europe and this is most marked in routine testing for and treatment of MG-associated PID, factors influencing the choice of antibiotic therapy, and action taken when an intrauterine device or system is in situ. Full results will be available by the conference.

Conclusion The management of PID varies across Europe and is not always in line with current European guidelines. There is a need for ongoing Europe wide education to ensure that patients are receiving evidence based care. Furthermore, there are issues

\begin{tabular}{|c|c|c|c|c|c|c|c|}
\hline Criterion & 2007 & 2008 & 2009 & 2011 & 2012 & 2013 & 2014 \\
\hline 1) All patients treated for GC should be recommended to have a test of cure (TOC) & & & & $\begin{array}{l}\text { (36\% had } \\
\text { a TOC) }\end{array}$ & $\begin{array}{l}91 \%(66 \% \text { had } \\
\text { a TOC) }\end{array}$ & $\begin{array}{l}84.6 \%(52.9 \% \\
\text { had a TOC) }\end{array}$ & $\begin{array}{l}91 \%(60 \% \\
\text { had a TOC) }\end{array}$ \\
\hline $\begin{array}{l}\text { 2) All patients with gonorrhoea should be screened for genital infection with Chlamydia } \\
\text { trachomatis or receive presumptive treatment for this infection }\end{array}$ & $100 \%$ & $100 \%$ & $100 \%$ & $98.6 \%$ & $100 \%$ & $100 \%$ & $100 \%$ \\
\hline $\begin{array}{l}\text { 3) All patients identified with gonorrhoea should have partner notification carried out } \\
\text { according to the published standards of the BASHH Clinical Standards Unit }\end{array}$ & $82 \%$ & $95 \%$ & $92 \%$ & $92 \%$ & $88 \%$ & $90.4 \%$ & $93 \%$ \\
\hline $\begin{array}{l}\text { 4) All patients identified with gonorrhoea should be offered written advice about STls } \\
\text { and their prevention }\end{array}$ & $32 \%$ & $64 \%$ & $81 \%$ & $61 \%$ & $50 \%$ & $66 \%$ & $27 \%$ \\
\hline $\begin{array}{l}\text { 5) All patients with gonorrhoea should receive first-line treatment, or the reasons for } \\
\text { not doing so should be documented }\end{array}$ & $77 \%$ & $96 \%$ & $100 \%$ & $97 \%$ & $88 \%$ & $100 \%$ & $97 \%$ \\
\hline
\end{tabular}


in clinical practice which are currently not covered by the European guidelines and these need to be reviewed to provide physicians with appropriate guidance.

\section{P127 SPECIAL INTEREST CLINIC: A NOVEL GENITOURINARY MEDICINE SERVICE INITIATIVE PROVIDING CONTINUITY OF CARE AND EDUCATIONAL OPPORTUNITIES}

Vian Shafiq*, Jonathan Shaw, Ashish Sukthankar. Manchester Centre for Sexual Health, Manchester, UK

\subsection{6/sextrans-2015-052126.170}

Introduction External referral to dermatology and psychosexual services from genitourinary medicine (GUM) can cause delays in patient care. To counter this within our service an experienced consultant has established a Special Interest Clinic (SIC) reviewing dermatology, erectile dysfunction and complex GUM cases. Written educational feedback is offered to internal referrers. We reviewed the impact of SIC.

Aims To evaluate the service offered by SIC.

Methods Data was collated from randomly selected patient records who attended SIC between April 2012 and April 2013.

Results A total of 100 records were reviewed. 67 patients were male, 25 of whom were MSM. Patients were ethnically diverse, White British (52) being the most common ethnicity. Median age was 33 years (range 19-70). 12 patients were HIV-infected. Internal referrals predominated (96) and average waiting time from referral was 6.2 weeks (range $0.14-28$ ). Broadly stratifying referrals 40 patients were complex GUM, 35 psychosexual medicine, 25 dermatology. The most prevalent diagnoses were erectile dysfunction (23) and lichen sclerosus (9). 9 patients required skin biopsy, 8 of which were performed within SIC. Ongoing follow up was recommended to 60 patients, of which $43(71.7 \%)$ were retained. 27 patients were discharged after first attendance. 77 referrers requested feedback, all received it.

Conclusion Keeping patients within our service provided continuity of care. The availability of formal feedback increases educational opportunities for referrers. We recommend experienced clinicians consider establishing similar SICs in other services. A challenge services will encounter is the lack of specific SHHAPT coding for prevalent SIC diagnoses.

\section{P128 MEETING STANDARDS IN MANAGEMENT OF SEXUAL ASSAULT: ARE WE THERE YET?}

Sujeevani Munasinghe, Malaki Ramogi*, Noellette L'Esperance. Colchester Hospital University Foundation Trust, Essex, UK

\subsection{6/sextrans-2015-052126.171}

Background/introduction Effective management of victims of sexual assault is important to encourage people to report abuse and receive care. BASHH provide guidance on management of sexually assaulted patients. We reviewed case notes of 36 patients who were treated for sexual assault.

Aim(s)/objectives

- To identify demographic characteristics of sexually assaulted victims attending the clinic.

- To understand how we meet the BASHH guidance (2011) in the management of sexual assaults.

- To assess the usefulness of locally used template for cases of sexual assault
Methods Case notes of 36 patients treated for sexual assault who attended the clinic from January 2013 to March 2014 were reviewed. A questionnaire was designed to collect data and the data was analysed using Microsoft excel.

Results 44 case notes were identified but 36 cases fulfilled the inclusion criteria. Of the 14 auditable outcomes, only documentation of essential criteria (standard 1) reached the 100\% standard and six achieved above $75 \%$ of the expected standard of $100 \%$. These include documentation of physical injuries, selfharm risk assessment, offer of emergency contraception, offer of active vaccination against Hepatitis B and assessment of child protection need. Offer of baseline STI screening was documented in $72 \%$. Poor documentation of BASHH criteria on further referral for physical injuries (33\%) and repeat testing for STIs (36\%) were identified.

Discussion/conclusion Importance of complete documentation on sexual assault cases should be emphasised. Reviewing the sexual assault template to capture all necessary information was identified as a result of this audit.

\section{P129 SHARED CLINICAL PRIORITIES IN AN INTEGRATED SEXUAL HEALTH SERVICE}

Gordon Scott*. Chalmers Sexual Health Centre, Edinburgh, UK

\subsection{6/sextrans-2015-052126.172}

Background/introduction Demand exceeds capacity in many sexual health services. In response to this, our GUM department developed a triage policy based on agreed clinical priorities. When we integrated with the local Sexual and Reproductive Health (SRH) service, which had its own more loosely defined priorities, an essential part of the process was to agree shared clinical priorities.

Aim(s)/objectives To create a single, agreed set of priorities across an integrated sexual health service.

Methods We reviewed the existing GUM priorities, and agreed they were still applicable. We created a formal set of SRH priorities. We merged the two into an integrated set of clinical priorities that would apply across the whole service.

Results The existing GUM priorities were patients with or at significant risk of HIV, followed by patients with or at significant risk of syphilis, then gonorrhoea, then chlamydia. The SRH priorities were widespread provision of long-acting reversible contraception (LARC), followed by emergency contraception (especially IUD), high quality abortion service, services for young people and services in more deprived areas. The single, agreed set of priorities for the integrated service were HIV-positive patients, women with unplanned pregnancy and under 16's; followed by patients at high risk of HIV, high risk of unplanned pregnancy, and/or people living in areas of high deprivation.

Discussion/conclusion Creating shared priorities has proved invaluable when pressure on the service builds up. Both services had to shed priorities that might have hitherto been regarded as "sacrosanct".

\section{P130 DOES USE OF A PRO FORMA IMPROVE MANAGEMENT OF COMPLAINANTS OF SEXUAL ASSAULT?}

Rachel Caswell ${ }^{*}$, Christine Hardwick, Penny Goold. Whittall Street Clinic, Birmingham, UK

10.1136/sextrans-2015-052126.173 